\title{
An umbrella arrives toward the end of the storm: Patient-tailored aspirin dosing improves late perioperative thromboprophylaxis
}

\author{
David Bichell, MD, and Muhammad A. Raees, MBBS
}

\author{
From the Department of Cardiac Surgery, Monroe Carell, Jr, Children's Hospital, Vanderbilt University Medical \\ Center, Nashville, Tenn. \\ Disclosures: Authors have nothing to disclose with regard to commercial support. \\ Received for publication July 7, 2017; accepted for publication July 14, 2017; available ahead of print Aug 29 , \\ 2017. \\ Address for reprints: David Bichell, MD, William S. Stoney, Jr, Department of Cardiac Surgery, Monroe Carell, Jr, \\ Children's Hospital, Vanderbilt University Medical Center, 2200 Children's Way, Nashville, TN 37232-9292 \\ (E-mail: david.bichell@vanderbilt.edu). \\ J Thorac Cardiovasc Surg 2017;154:1731-2 \\ $0022-5223 / \$ 36.00$ \\ Copyright (C) 2017 Published by Elsevier Inc. on behalf of The American Association for Thoracic Surgery \\ http://dx.doi.org/10.1016/j.jtcvs.2017.07.031
}

Cardiac arrest, reintervention, stroke, sepsis, and chylothorax are demons sabotaging postoperative recovery and are all associated with perioperative thrombotic events. Difficult to prevent, or even to detect, thrombotic complications remain among our most important unsolved problems. Effective prevention demands more of the kind of patient-tailored approaches that Emani and colleagues ${ }^{2}$ report in this issue of the Journal.

Emani and colleagues ${ }^{2}$ have retooled standard aspirin thromboprophylaxis, with point-of-care sensitivity testing, dose escalation for subresponders, and a resultant reduction in thrombotic events. Prophylactic aspirin, dose optimized, is an improved demon repellent for patients receiving enteric feeds. ${ }^{2}$

But it is only those who first succeed at tiptoeing across a minefield who enjoy the advantage. Luck is required to reach the point of oral feeds before experiencing a thrombotic complication from the array of earlier perioperative risks.

Neonates, arriving with a procoagulant attitude (thrombocytopenia, deficient factors II, V, VII, VIII, X, antithrombin, and protein $\mathrm{C}$, elevated $\mathrm{C}$-reactive protein) and then subjected to hypoxia, hemodynamic lability, endothelial damage, and the introduction of foreign material to the bloodstream, have cascading provocation to clot even before the insult of surgery. ${ }^{3}$

Central venous lines (CVLs) are associated with approximately $90 \%$ of neonatal thrombotic events. ${ }^{4}$ Nearly all CVL-related deep vein thrombosis occurs within 1 to 2 days of line placement. ${ }^{5}$ Ultrasound and venography underestimate the prevalence of these consequential, if often silent risks. ${ }^{6}$

Excluded from the analysis in the current study were 23 patients who experienced thrombotic events before their introduction to aspirin, meaning 34 thrombotic events affected the study population. ${ }^{2}$ Twice as many thrombotic

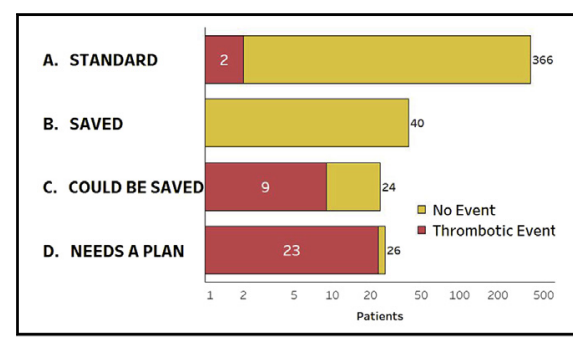

A, Aspirin responsive. B, Resistant, dose increased. C, Resistant, no increase. D, Not analyzed.

\section{Central Message}

Point of care testing and dose adjustment of aspirin show promise for reducing thrombotic complications late in the hospital course. Patient-tailored early perioperative thromboprophylaxis remains an important challenge.

See Article page 1723.

events occurred in the risk-laden preoperative and early postoperative periods, as did after the start of aspirin, despite multimodal therapies applied (Figure 1).

Early perioperative thromboprophylaxis with unfractionated heparin or enoxaparin is highly variable and of unproven efficacy. Level $\mathrm{C}$ evidence supports the use of low-dose heparin after shunt construction. ${ }^{7}$ Conflicting data question the efficacy of heparin thromboprophylaxis for CVLs. ${ }^{8,9}$ Neonates need higher enoxaparin dosing to achieve therapeutic anti-Xa levels than do older children. ${ }^{10}$ Antithrombin III deficiency is costly to measure and to replete, and the effectiveness of a strategy of heparin with antithrombin III repletion therapy is unproven in preventing thrombus. ${ }^{11}$ The strongest recommendation for neonatal thrombus prevention is to get CVLs out, which often is not an option. ${ }^{7}$

The opportunity to improve early intensive care unit thromboprophylaxis with patient-specific sensitivity data, analogous to the work that Emani and colleagues ${ }^{2}$ have done with aspirin, will depend on the development of better measures, better agents, or possibly less thrombogenic CVLs.

One size does not fit all. Emani and colleagues ${ }^{2}$ demonstrate that individual variation in aspirin responsiveness can be measured in real time with point-of-care testing, and effective dose adjustment may mitigate risk. Controversial and widely variable practices are applied to clot prevention in the earlier perioperative period, when 


\section{A. STANDARD}

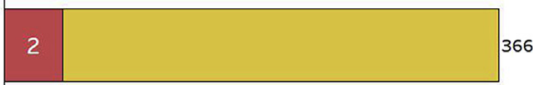

B. SAVED

C. COULD BE SAVED

D. NEEDS A PLAN
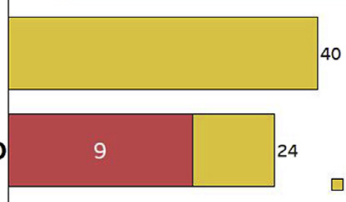

$\square$ No Event

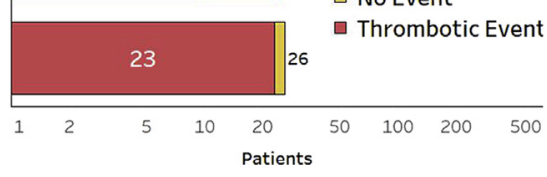

FIGURE 1. Data extrapolated from Emani and colleagues, ${ }^{2}$ showing 23 thrombotic events occurring before the introduction of aspirin and therefore excluded from analysis. A, Aspirin responsive. B, Resistant, dose increased. C, Resistant, no increase. D, Not analyzed.

risk may be highest and patient-to-patient variability drives uneven results with important consequences. Patient-specific, data-driven custom approaches are lacking for effective thromboprophylaxis in the highest risk period for these infants.

\section{References}

1. Manlhiot C, Menjak IB, Brandão LR, Gruenwald CE, Schwartz SM, Sivarajan VB, et al. Risk, clinical features, and outcomes of thrombosis associated with pediatric cardiac surgery. Circulation. 2011;124:1511-9.
2. Emani S, Zurakowski D, Mulone M, DiNardo JA, Trenor CC III, Emani S. Platelet testing to guide aspirin dose adjustment in pediatric patients following cardiac surgery. J Thorac Cardiovasc Surg. 2017;154:1723-30.

3. Cholette JM, Rubenstein JS, Alfieris GM, McDermott MP, Harmon WG, Vermilion R, et al. Elevated risk of thrombosis in neonates undergoing initial palliative cardiac surgery. Ann Thorac Surg. 2007;84:1320-5.

4. Schmidt B, Andrew M. Neonatal thrombosis: report of a prospective Canadian and international registry. Pediatrics. 1995;96(5 Pt 1):939-43.

5. Schmugge M, Bang KWA, Blanchette VS, Albisetti M, Connolly BL, Freedman J, et al. Platelet activation and von Willebrand factor binding to platelets in newborn infants with central venous lines. Acta Haematol. 2007; $117: 145-8$.

6. Male C, Chait P, Ginsberg JS, Hanna K, Andrew M, Halton J, et al. Comparison of venography and ultrasound for the diagnosis of asymptomatic deep vein thrombosis in the upper body in children results of the PARKAA Study. Thromb Haemost. 2002;87:593-8.

7. Giglia TM, Massicotte MP, Tweddell JS, Barst RJ, Bauman M, Erickson CC, et al. Prevention and treatment of thrombosis in pediatric and congenital heart disease: a scientific statement from the American Heart Association. Circulation. 2013;128:2622-703.

8. Massicotte MP, Randolph A, Bauman M. Central venous line thromboprophylaxis: transforming "experience-based care" into "evidence-based care" J Intensive Care Med. 2011;25:341-2.

9. Schroeder AR, Axelrod DM, Silverman NH, Rubesova E, Merkel E, Roth SJ. A continuous heparin infusion does not prevent catheter-related thrombosis in infants after cardiac surgery. Pediatr Cric Care Med. 2010;11:489-95.

10. Chander A, Nagel K, Wiernikowski J, Paes B, Chan AK. Thrombosis and Hemostasis in Newborns (THiN) Group. Evaluation of the use of low-molecular-weight heparin in neonates: a retrospective, single-center study. Clin Appl Thromb Hemost. 2013;19:488-93.

11. Corder A, Held K, Oschman A. Retrospective evaluation of antithrombin III supplementation in neonates and infants receiving enoxaparin for treatment of thrombosis. Pediatr Blood Cancer. 2014;61:1063-7. 